\title{
DETC2010-28713
}

\section{IMPACT OF ENERGY MEASUREMENTS IN MACHINING OPERATIONS}

\author{
Minna Lanz, Mahesh Mani, \\ Swee Leong, Kevin Lyons \\ Manufacturing Systems \\ Integration Division, National \\ Institute of Standards and \\ Technology, \\ Gaithersburg, MD, US
}

\author{
Ari Ranta, Kimmo Ikkala \\ Department of Production \\ Engineering, Tampere University \\ of Technology \\ Tampere, Finland
}

\author{
Nils Bengtsson \\ Production Modeling \\ Corporation, \\ Gothenburg, Sweden
}

\begin{abstract}
Over the past years, institutions in general are increasingly interested and involved in sustainability and social responsibility. In addition, social and political pressures have led to the creation of new regulations and policies that support new business opportunities around global sustainability. Considering sustainable manufacturing, a number of indicators have been proposed and currently being researched.

The aim of this paper is to explore and discuss the impact of energy measurements as an indicator for sustainable manufacturing. The main question to be asked is, can energy measurement be used for optimization the machining level process. Based on energy monitoring during two Computer Numerical Control (CNC) machining case studies, the significance of energy cost based on different CNC machining strategies and parameter settings is examined and discussed.

The preliminary results from the energy measurements on the case studies indicate that potential cost savings in energy will be minimal in CNC operations. Based on the case studies, the potential energy savings in monetary value do not necessarily justify a company's investment in implementing real time energy tracking technologies; however the results were limited in scope with regards measuring energy as an indicator for evaluating other performance outcomes.
\end{abstract}

\section{INTRODUCTION}

Historically the optimization of machining operations has been limited to objective functions related to cost, productivity, and quality of products, which involve the optimum selection of machining conditions, e.g., cutting speed, feed, depth of cut $[3,5,14]$, cost and throughput time. For optimizing those parameters there exist several methods such as utilization of Genetic Algorithms (GAs) in optimization [5, 11], fuzzy logic [14] or on-line optimization based on measurements [12]. The latest optimization efforts have been focused on extending the tool-life as main process performance objectives [11]. However, at the turn of the third millennium, rising public awareness of economic, social, environmental, and technological problems have brought sustainable development and its main enabler, manufacturing, back to the political agendas. The traditional optimization of processes may not be enough for a company to ensure that their processes and operations meet the requirements set by sustainability regulations and expectations. For example, according to Jovane [13], the European Commission (EC) has funded various programs dealing with challenges faced by the new need of competitive sustainable manufacturing development.

In order to offer effective and continued support to U.S. companies in their sustainable manufacturing efforts, the U.S. Department of Commerce's Manufacturing \& Services unit has launched a Sustainable Manufacturing Initiative (SMI) and Public-Private Dialogue that aims to a) identify U.S. industry's most pressing sustainable manufacturing challenges and b) coordinate public and private sector efforts to address these challenges [19].

The Organization for Economic Co-operation and Development's (OECD) project on sustainable manufacturing and eco-innovation aims to accelerate sustainable manufacturing by diffusing knowledge and providing industry with a means to measure its progress in a simple and comprehensive way.

The U.S. Department of Commerce uses the following definition for sustainable manufacturing: Sustainable manufacturing is defined as the creation of manufactured 
products that use processes that are non-polluting, conserve energy and natural resources, and are economically sound and safe for employees, communities, and consumers [7].

According to the National Council for Advanced Manufacturing (NACFAM) [17] perspective, there are two distinctions in the way sustainable manufacturing is referred. First, sustainable manufacturing includes the manufacturing of sustainable products and second, sustainable manufacturing includes the manufacture of all products produced using sustainable practices. The former includes manufacturing of renewable energy, energy efficiency, green building, and other green and social equity-related products.

The EC launched new programs under the Framework Programme 7 (FP7) call. Objective for the factories of the future FoF.ICT.2010.10-1: Smart Factories: Information and Communication Technologies (ICT) for agile and environmentally friendly manufacturing is to focus on applications based on context- and user-aware ICT and scalable networks of sensors, exhibiting features such as energy autonomy, wireless connectivity, self-configuration, diagnosis and repair integrated in machines, factory-level infrastructure, real-time monitoring of energy use, and material flow [9]. Work should aim at promoting standardsbased approaches in conjunction with international initiatives involving industry groups and standardization bodies.

Shahbazpour and Seidel (2006) summarized in their research on an analysis of the reasons companies are enthusiastically embracing sustainability:

- Legitimating - the desire to improve suitability of the firm's actions within an established set of regulations, norms and values

- Moral responsibility - the desire that stems from the concerns a firm has for its social obligations arising from its self-perception as a functional entity within the macro economical, social, and natural environments

- Competitiveness - the desire to improve the potential for profitability through developing resources and capabilities that are difficult to imitate

Shahbazpour and Seidel (2006) also stated that regardless of the motive, by adopting socially responsible and sustainable objectives, companies can improve their competitiveness where manufacturing plays an important role.

The study [15] has shown that it is possible to trace the energy consumption and assign an energy profile to a part or product going all the way to the feature level. It also seemed possible to optimize the process sequence based on energy consumption. By utilizing the measured values, it is in theory possible to design part features to be less energy intensive to manufacture. Mani [15] also described the opportunities for utilization of energy monitoring as an asset for Computer Aided Process Planning (CAPP):

- $\quad$ Energy efficiency between facilities

- Energy efficiency between routing scenarios

- Optimal scheduling plan based on energy efficiency
However, for machining, the same study has shown that the total energy savings for designing a feature to be energy conservative is not significant at the full system scale. Manufacturing is much more than the amount of energy consumed over a given time period. Solely focusing on the difference between two alternative ways to produce a part based on energy consumption might shift the focus away from other more significant issues such as cycle time, idle time, material waste, toxic materials, material recycling and production facility in general. Energy consumption measurement can serve as one performance indicator by comparing the difference between the initial state and the end state of the line. The authors would like to emphasize that applying proven practices such as the principles of LEAN [6], Beyond Lean [6], and Monozukuri that emcompases LEAN philosophy and sustainability theorems[10], companies can focus on enterprise-level optimization rather than local optimization.

\section{MANUFACTURING ENERGY AND IMPLICATIONS}

Manufacturing processes utilize energy and other resources to transform raw materials and intermediates into final products. From an economic viewpoint, energy enables the manufacturing operations that add value to intermediate products as they are progressively transformed into final consumer goods. Energy efficient manufacturing equipment saves energy and/or generates the energy during the operation without reducing the levels of service [15].

According to Mani [15] the energy cost represents a considerable amount of the total production cost and therefore energy savings have become a major concern for manufacturing companies. Anderberg et al. [3] summarized in their research that the development of manufacturing methodologies have resulted in a steady growth of energy consumption in the manufacturing sector. This has resulted in a major concern for the manufacturing industry due to the energy and the associated environmental impact reduction required, in particular carbon emission, as a result of international agreements such as the Kyoto Agreement [3].

There exists opportunities to dig deeper into manufacturing processes for identifying the targets for energy savings. According to [3], manufacturing processes are generally poorly documented in terms of their energy and ecoefficiency. Often, the fixed energy consumption due to unloaded motors, coolant pumps, controllers, fans, and other peripheral equipments are not taken into account when discussing energy efficiency. In addition, the energy requirements depend on the production rate and are consequently not constant. The lack of thorough analysis of manufacturing processes may have major consequences, as opportunities are often not recognized in terms of energy and carbon emission reduction necessary to achieve key targets set by the government.

\section{TRADE-OFF BEHIND THE DECISION MAKING}


The focuses in the field of sustainable development are in reducing waste and carbon emissions, conserving energy, conserving natural resources, and reducing business impact on ecosystems. Thus manufacturing can be seen as having conflicting instances due to the utilization of resources and energy while producing emissions and waste. The conflicts in sustainability can be analyzed via trade-offs - conflict between two or more competitive objectives whereby superior performance in one results in lower performance in another.

Trade-offs play an important role in planning and evaluating manufacturing operations. The debate over the notion that trade-offs inherently exist in the domain of manufacturing cannot be eliminated or can be seen as multiple reachable objectives. Shahbazbour and Seidel [18] stated that trade-offs could be seen as a complex set of relations and constraints that can be removed in order to reach higher levels of performance. They also stated that for the purpose of improving or eliminating trade-offs, it would be more useful to view the contradicting relationships between instances in terms of opposing correlations they have with the systems parameters. Such contradicting relationship is the root-cause of the trade-off.

Sustainability as a manufacturing objective can have a trade-off relationship with other competitive objectives when and where the relationship between sustainability and systems parameters such as resources, energy, material, waste, and emissions is in contradiction with the relationship between other objectives and parameters [18].

Some examples of trade-off analyses are described below:

- The material choice and manufacturing process settings that result in best quality of the product lead to an increase in air pollution and manufacturing cost [4].

- The effort of reducing material costs and solid waste material also conflict with the goals to reduce processing times and carbon emission levels [4].

\section{CASE STUDIES IN MANUFACTURING}

\subsection{Case 1 - Energy measurements in drilling and} turning of steel

This case study was done in Tampere University of Tampere's heavy laboratory with Gildemeister CTX alpha 500 connected to Siemens 840D SL controller. The aim of the study was to inspect how fast the set-up for measuring energy consumption could be done and how CNC machining parameters such as speed, feed, and cutting tool condition affect energy consumption for this particular CNC machining center.

The material used in the turning test was round steel bar IMATRA 520. And the case product's shape was cylindrical and the main interest was it's surface quality. This experiment required two researchers and two days to setup the measuring instruments and install the necessary software tools for one CNC center. The energy meter used in this test was Carlo Gavazzi EM21. The set up is illustrated in the Figure 1.

The following graphs show what kind of values can be achieved from the energy measurements done for a single CNC machine. Figure 2 illustrates the amount of power spent (Active, Reactive and Complex power) in time dT in relation to the spindle's revolution speed (rpm) while producing the test part.

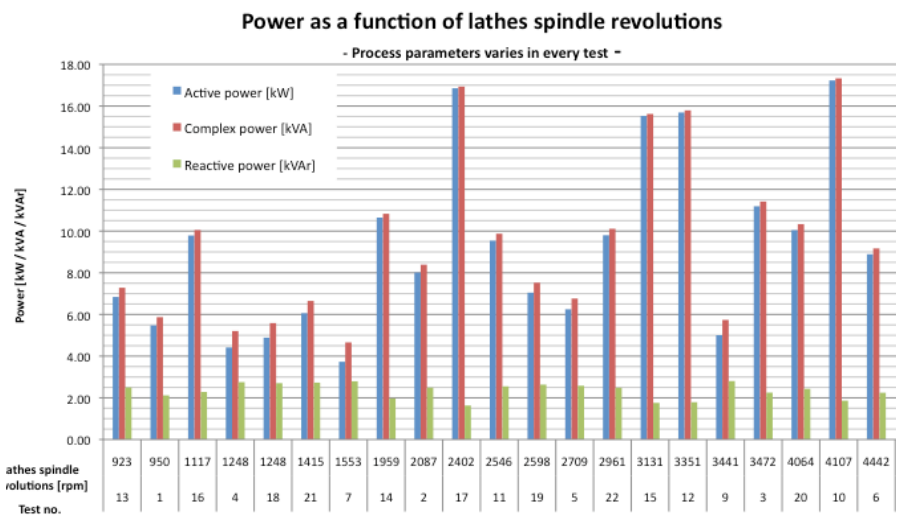

Figure 2: Power as a function of spindle revolutions

Figure 3 indicates the power used as a function of material removal rate, i.e., chip flow.

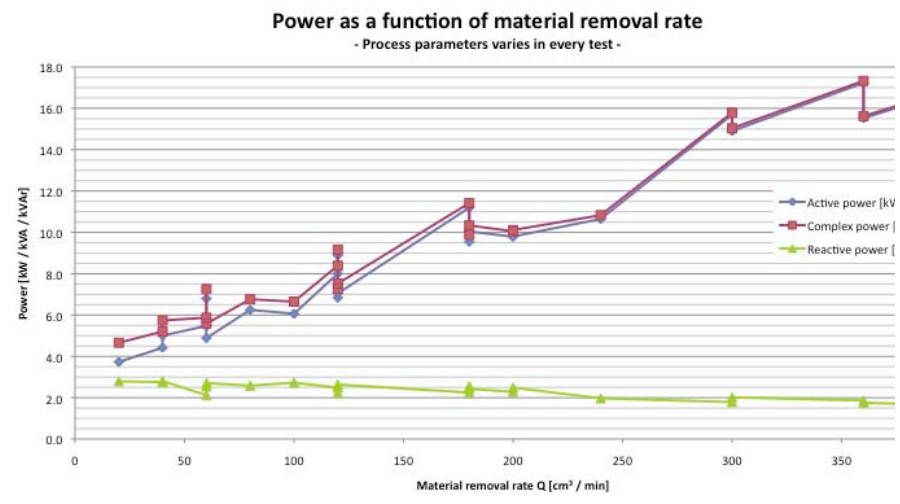

Figure 3: Power as a function of material removal rate

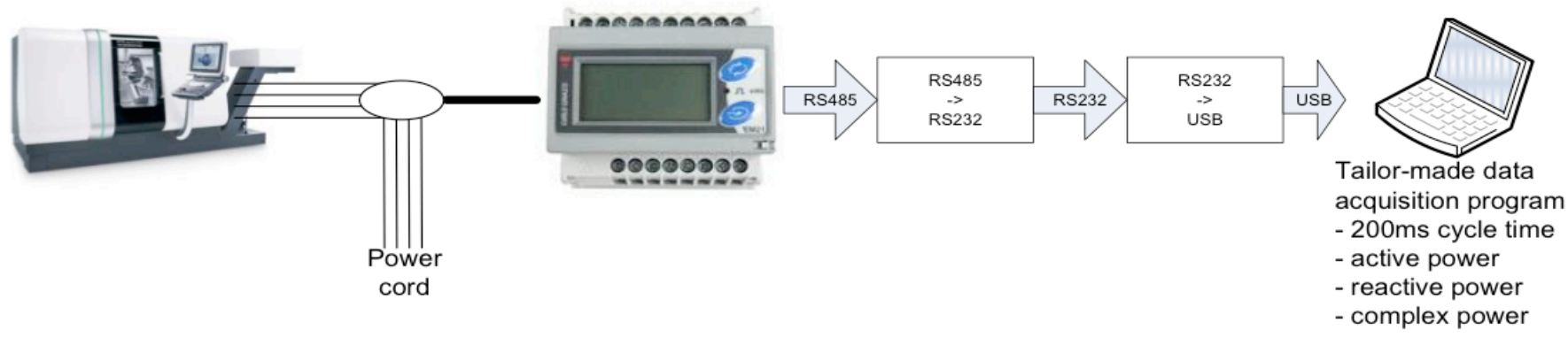

Figure 1: Set up for test 
Active power consumption in $\mathrm{kW}$ compared with cutting speed and axial depth is represented in Figure 4. Aside the measuring of the power consumption the chart from Figure 4, for example, is used for determining the optimal parameters for cutting.

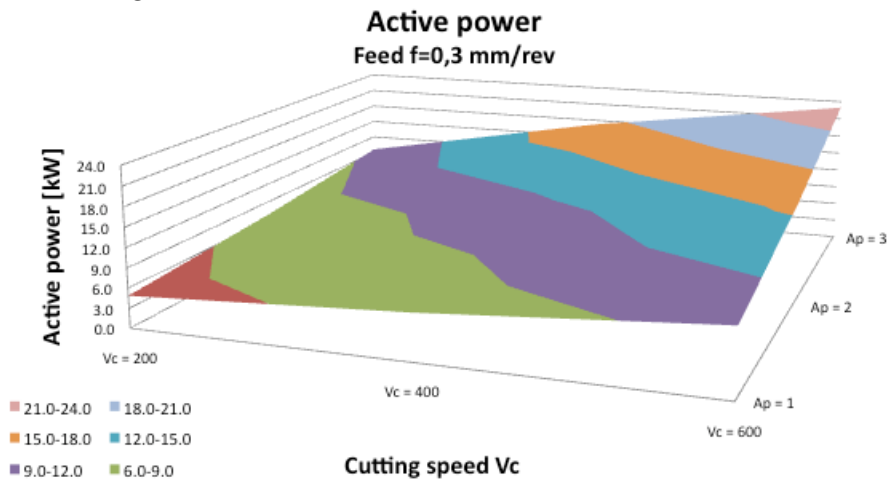

$=3.0-6.0=0.0-3.0$

Figure 4: Active power is function of cutting speed and axial depth

The Figure 5, on the other hand shows the P/Q ratio for representing material removal as a function of power, where the $\mathrm{Q}$ stands for amount of removed material and $\mathrm{P}$ for active power used.

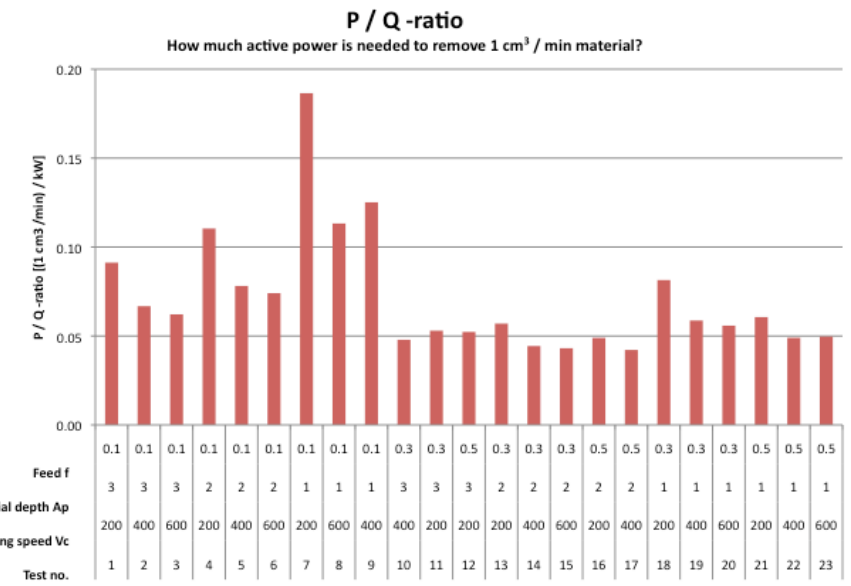

Figure 5: $P / Q$ ratio for representing how much power is needed to remove $1 \mathrm{~cm} 3$ volume of material per minute

From the experiments it can be summarized that measuring the energy consumption for CNC operations is fairly simple and a straightforward process. However, using energy as one of the CNC operation optimization parameters is questioned. Figure 6 shows a multi-variable analysis between CNC process quality, material removal rate $\mathrm{Q}$ and $\mathrm{P} / \mathrm{Q}$-ratio, and Table 1, the actual values. The values in Table 1 as well as in the Figure 6 are organized based on the material removal rate.

Figure 6 illustrates that the CNC process itself must be near optimal in order to reach the best solution possible according to the chosen trade-off scenario. The quality of the product has highest relevance, since the scrap equals to energy wasted. The result of the multivariable analysis showed that the two tests, 13 and 14, resulted in the required process quality. The amount of energy used for removing $120 \mathrm{~cm}^{3} / \mathrm{min}$ was $6.84 \mathrm{~kW}$ and removing $240 \mathrm{~cm}^{3} / \mathrm{min}$ was $10.65 \mathrm{~kW}$, but for test 13 material removal rate was low. By comparing tests 10 and 15 , the test 15 showed slightly better P/Q ratio.

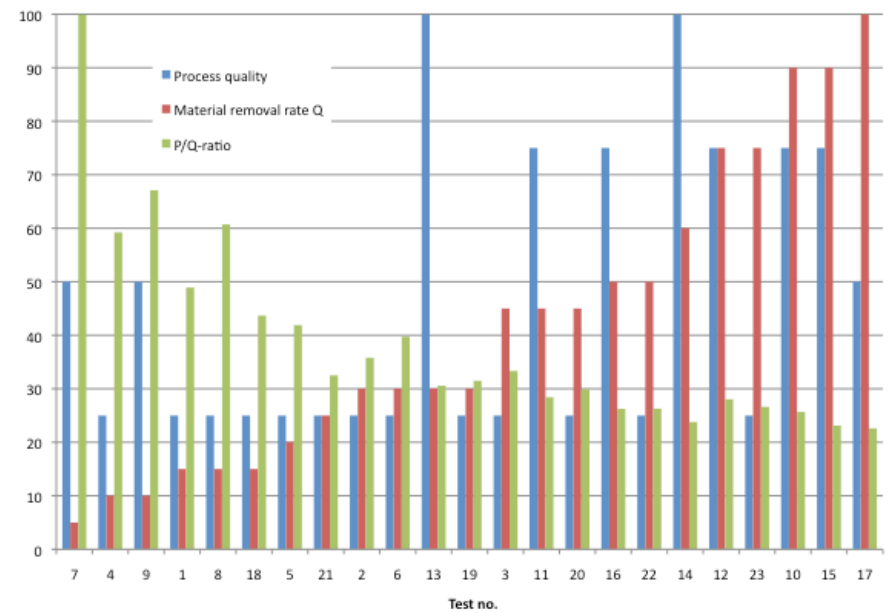

Figure 6: Multi-variable analysis between CNC process quality, material removal rate $Q$ and $P / Q$-ratio.

Table 1 Corresponding values for Figure 5

\begin{tabular}{|c|c|c|c|c|c|c|}
\hline \multirow{2}{*}{$\begin{array}{c}\text { Test } \\
\text { no. }\end{array}$} & \multicolumn{2}{|c|}{ Process quality } & \multicolumn{2}{c|}{ Material removal rate Q } & \multicolumn{2}{c|}{ P/Q-ratio } \\
\hline & $1 . .4 "$ & $0 \ldots 100 \%$ & {$\left[\mathrm{~cm}^{3} / \mathrm{min}\right]$} & $0 \ldots 100 \%$ & {$\left[\mathrm{~kW} /\left(\mathrm{cm}^{3} / \mathrm{min}\right)\right]$} & $0 . .100 \%$ \\
\hline 7 & 2 & 50 & 20 & 5 & 0.187 & 100.0 \\
\hline 4 & 1 & 25 & 40 & 10 & 0.110 & 59.2 \\
\hline 9 & 2 & 50 & 40 & 10 & 0.125 & 67.1 \\
\hline 1 & 1 & 25 & 60 & 15 & 0.091 & 48.9 \\
\hline 8 & 1 & 25 & 60 & 15 & 0.113 & 60.7 \\
\hline 18 & 1 & 25 & 60 & 15 & 0.081 & 43.7 \\
\hline 5 & 1 & 25 & 80 & 20 & 0.078 & 41.9 \\
\hline 21 & 1 & 25 & 100 & 25 & 0.061 & 32.5 \\
\hline 2 & 1 & 25 & 120 & 30 & 0.067 & 35.8 \\
\hline 6 & 1 & 25 & 120 & 30 & 0.074 & 39.7 \\
\hline \hline 13 & 4 & 100 & 120 & 30 & 0.057 & 30.6 \\
\hline \hline 19 & 1 & 25 & 120 & 30 & 0.059 & 31.5 \\
\hline 3 & 1 & 25 & 180 & 45 & 0.062 & 33.3 \\
\hline 11 & 3 & 75 & 180 & 45 & 0.053 & 28.4 \\
\hline 20 & 1 & 25 & 180 & 45 & 0.056 & 29.9 \\
\hline 16 & 3 & 75 & 200 & 50 & 0.049 & 26.2 \\
\hline 22 & 1 & 25 & 200 & 50 & 0.049 & 26.3 \\
\hline \hline 14 & 4 & 100 & 240 & 60 & 0.044 & 23.8 \\
\hline \hline 12 & 3 & 75 & 300 & 75 & 0.052 & 28.0 \\
\hline 23 & 1 & 25 & 300 & 75 & 0.050 & 26.6 \\
\hline \hline 10 & 3 & 75 & 360 & 90 & 0.048 & 25.7 \\
\hline \hline 15 & 3 & 75 & 360 & 90 & 0.043 & 23.1 \\
\hline \hline 17 & 2 & 50 & 400 & 100 & 0.042 & 22.6 \\
\hline
\end{tabular}

Since the goal of the study was to define the best CNC process parameters and observe the energy consumption and it's relevance for determining optimal parameters, continuous CNC process observation was not conducted. During the test the active power consumption was between $4.42 \mathrm{kWh}$ and $17.31 \mathrm{kWh}$. The lathe's IDLE time's power consumption is $1.67 \mathrm{~kW}$, which is $8.4 \%$ of the CNC machine's continuous drive power.

It can be summarized that a sustainable manufacturing paradigm does not necessarily disagree with the efficient and productive manufacturing, but the major savings will primarily come from good production planning. And especially the energy and cost savings will come from minimizing the non-productive and non-value add time of the products such as the CNC machine's idle time or long set-up times for parts. 
4.2. Case 2 - Energy measurements in machining aluminum and titanium

A project was conducted at NIST together with the Boeing Company using MTConnect ${ }^{\mathrm{TM}}$, a new factory floor integration specification, sponsored by the Association for Manufacturing Technology (http://www.MTConnect ${ }^{\mathrm{TM}}$.org/). The objective was to collect data from the CNC machines and use that data in a Discrete Event Simulation model for analysis of the CNC machining operations. MTConnect ${ }^{\mathrm{TM}}$ was used to transmit information measured at the machine tool such as spindle load, axis loads, together with the rotary loads of the machine. This data, along with the CNC machine specification, was used to calculate the instantaneous energy consumption of the CNC machine at various time intervals.

Data from high speed CNC machining (> 18,000 RPM) of aluminum together with CNC machining of titanium was analyzed during the project. All data was collected from the CNC machines during normal production. The data from the high speed CNC machining of aluminum was taken from three equally equipped five axis Mazak CNC machines and the machine specifications are shown in Table 2.

Table 2 Machine specification for Aluminum

\begin{tabular}{|l|l|}
\hline Machine part & Output $(\mathrm{kW})$ \\
\hline Spindle & 15.0 \\
\hline X-axis & 3.5 \\
\hline Y-axis & 3.5 \\
\hline Z-axis & 3.5 \\
\hline A-axis & 1.0 \\
\hline C-axis & 1.0 \\
\hline Hydraulic pump & 1.5 \\
\hline Coolant pump & 0.37 \\
\hline Chiller & \\
\multicolumn{1}{|c|}{$\begin{array}{l}\text { Spindle } \\
\text { Chiller unit }\end{array}$} & 0.4 \\
\multicolumn{1}{|c|}{ Fan } & 0.1 \\
\hline Chip conveyor & 0.2 \\
\hline Magazine rotational motor & 0.6 \\
\hline ATC drive motor & 0.4 \\
\hline Total power & $\mathbf{3 2 . 2 2}$ \\
\hline
\end{tabular}

Only the energy for spindle and axis were included in the case study yet other output can be added as a worst-case scenario if wanted from the machine specification. The data of cutting titanium was taken from a single five axis Mazak CNC machine, and the machine specification is shown in Table 3. The energy consumption data from the machining centers are displayed in Table 4.

Table 3 Machine specification for Titanium

\begin{tabular}{|l|l|}
\hline Machine part & Output $(\mathrm{kW})$ \\
\hline Spindle & 55.0 \\
\hline X-axis & 4.5 \\
\hline Y-axis & 4.5 \\
\hline Z-axis & 7.0 \\
\hline A-axis & 7.0 \\
\hline C-axis & 7.0 \\
\hline
\end{tabular}

Table 4 Energy consumption from CNC machines

\begin{tabular}{|l|l|l|l|}
\hline $\begin{array}{l}\text { Machine } \\
\text { information }\end{array}$ & $\begin{array}{l}\text { Min value } \\
(\mathrm{kW})\end{array}$ & $\begin{array}{l}\text { Max value } \\
(\mathrm{kW})\end{array}$ & $\begin{array}{l}\text { Average } \\
\text { value }(\mathrm{kW})\end{array}$ \\
\hline $\begin{array}{l}\text { Idle } \\
\text { Aluminum }\end{array}$ & 1.0 & 4.0 & 1.7 \\
\hline $\begin{array}{l}\text { Machining } \\
\text { Aluminum }\end{array}$ & 0.4 & 23.0 & 2.9 \\
\hline Idle Titanium & 3.1 & 5.4 & 3.7 \\
\hline $\begin{array}{l}\text { Machining } \\
\text { Titanium }\end{array}$ & 0.7 & 16.3 & 4.7 \\
\hline
\end{tabular}

The $0.4 \mathrm{~kW}$ min value for CNC machining aluminum was surprising since it is lower than the minimum value of $1.0 \mathrm{~kW}$ for Idle, but it only appeared once. The second smallest value was $1 \mathrm{~kW}$, which corresponds better to the idle value of the machine. Yet another conflicting data is the minimum value of $0.7 \mathrm{~kW}$ for CNC machining Titanium compared to $3.1 \mathrm{~kW}$ at idle state. The second smallest value for CNC machining Titanium was $1.3 \mathrm{~kW}$, which is still significantly smaller then $3.1 \mathrm{~kW}$ for idle Titanium. The validity of values is considered with more detail in the chapter Discussion.

\section{CARBON WEIGHT AS AN INDICATOR OF ENERGY}

There exist several different ways to evaluate the energy consumption of a manufacturing process and aggregate those values to determine the carbon weight. Anderberg et al.[2] introduced a new, simple Carbon Emission Signature (CES) method. Knowing the CES for a power grid and the collective energy needed to make a part, the carbon emitted can be found. This is particularly important since in most cases, the manufacturing of a product is connected directly to the amount of carbon emitted in producing electrical energy for that manufacturing process. Based on the results from the energy measurements, either in real-time or a one-time event, it is a relatively straightforward process to convert the results to $\mathrm{CO}_{2}$ emissions for regulatory documents/proofs/predictions and or for financial purposes.

Carbon Weight (CW) often referred to as Carbon Footprint can be easily calculated. $\mathrm{CW}=f(\mathrm{E})$. $\mathrm{CW}$ is proportional to $\mathrm{E}$ and the proportionality factor is $f$ [1].

The Energy Information Administration (EIA) under the U.S. Department of Energy (DoE), has reported a methodology and related tables for computing factor $f[7,8]$. For Maryland, the value of $f$ is 0.620 metric tons/MWh. EIA reports $\mathrm{CO}_{2}$ emission in terms of metric tons. The factor $f$ is computed using the average energy mix available in each state of the USA and includes equivalent computations of impacts from emission of $\mathrm{CH}_{4}$ and $\mathrm{NO}_{x}$ into $\mathrm{CO}_{2}$.

\section{DISCUSSION}

Tracking manufacturing energy (from raw materials to product to end-of-life) is inherently a multi-faceted problem. Depending on the type of manufacturing, accounting and reporting energy only during the manufacturing phase may not show any significant savings on a business perspective. Energy measurement by itself or optimizing processes locally will not make a company more sustainable. Instead measured energy consumption can be used as an indicator for other 
things in the CNC cutting process as predicting tool wear, quality levels or new future applications that have the energy data available.

Nevertheless the authors do consider the energy savings as a highly important factor in the effort to make the manufacturing industry more sustainable. Based on the case studies presented here it is more appropriate to focus the energy saving goal on the system and facility level rather than optimizing locally to generate a win-win situation for the companies and the environment with lower cost and smaller environmental impact. The systems approach allows the energy implications to be considered with a much wider perspective.

The following bullets list some applications where the real time energy monitoring seems to be worth doing. The cases are such as:

- To predict machine behavior in a controlled environment for quality purposes

- To record and analyze machine-specific pattern of performance

- To evaluate, validate or predict the tool wear

- To utilize manufacturing energy consumption as investment guidance

It is more sustainable to reduce the idle time of CNC machines compared to optimizing the cutting processes since the idle time energy consumption does not add any value for the process. This connection between idle state and machining state shows that the traditional efficiency work in the manufacturing industry also indirectly targets sustainability aspects by increasing machine utilization and reduce waste.

One route for achieving sustainable manufacturing can be done via value stream mapping, where the processes are monetized and the difference between productive time and non-productive time can be clearly stated. By measuring the idle time that each machine spends waiting and translating this value to a carbon footprint, the energy consumption gets a tangible value. By decreasing the idle time and thus decreasing the energy waste is one of the backbones for a more sustainable manufacturing paradigm. And it is a measurable value.

Alongside considering the significance of measurements, the measuring methodology needs to be considered as well as the reliability of the results. For example, in the case study two, the energy data exchanged by MTConnect ${ }^{\mathrm{TM}}$ [16] had not been validated with independent measurement equipment; this opens up the possible incorrectness of the data. The results are however in line with the experimental results conducted in Finland and should therefore be a good indicator on how much energy a CNC machine is using in daily operations. The various results in the lowest value in the measured energy range can be due to sampling error. The used sampling rate is 10 seconds in the Case Study 2 and every value is an instantaneous value and data is collected over less than a 24 hour time-span. Another reason for the smaller values of machining compared to idle is that the idle state of the CNC machine is misinterpreted in the MTConnect ${ }^{\mathrm{TM}}$ data. MTConnect ${ }^{\mathrm{TM}}$ does not give a value if the machine is idle or not, instead assumptions are made based on when RPM $=0$, Feedrate $=0$, and a certain program is running when the machine is in idle state. These assumptions for idle state might not be accurate but it does not take away the fact of low average energy consumption overall in the CNC machines during machining and idle state as defined.

\section{SUMMARY}

The study results indicated that the energy monitoring and measuring efforts in the area of CNC does not have a forward relationship to the evaluation of a process's or company's sustainability level. The data from both case studies did show that the energy consumption in CNC operations is relatively easy to measure yet small in value. Put in financial terms, the energy cost for machining titanium is around 50 cent per hour based on the energy costs in the US. With this in mind, the financial impact on trying to optimize CNC cutting processes to reduce the energy will have little financial benefits and might cost more than it saves, since the payback from monitoring equipment and measuring costs must be covered as well.

It is also worth considering how much the facility's energy consumption will be due to the slower processing or the time spent on tool path and parameter optimization. The results indicate that manufacturing companies should focus their energy savings efforts on system level rather than single operation level for achieving high financial payback.

As conclusion, according to the possible solutions for measuring the energy consumption, the results that can be calculated give the numerical processing values. However, the results from the case studies do also fall short for demonstrating the significance of measuring energy for decision making, planning and evaluating energy efficient operations from a total sustainable systems perspective. The authors believe that energy monitoring in CNC machining should be investigated alongside other significant sustainable factors and manufacturing issues such as the idle time, material waste, toxic materials and material recycling.

\section{ACKNOWLEDGMENTS}

The authors would like to thank John Michaloski at the National Institute of Standards and Technology together with Sid Venkatesh at the Boeing Company for valuable discussions and providing the data used in Case Study 2.

\section{DISCLAIMER}

The work described was funded by the United States Government and is not subject to copyright. No approval or endorsement of any commercial product by the National Institute of Standards and Technology is intended or implied.

\section{REFERENCES}

[1] Aggarwal, A., and Singh, H., 2005. "Optimization of machining techniques - A retrospective and literature review", Sadhana, Vol 30:6, pp. 699-711.

[2] Ameta, G., Mani, M., Sudarsan, R., Feng, S.C., Sriram, R.D and Lyons K., 2009. "Carbon weight analysis for machining operation and allocation for redesign”, International Journal of Sustainable Engineering, Vol 2:4, pp 241 - 251. 
[3] Anderberg, S.E., Kara. S., Beno, T., 2010. "Impact of energy efficiency on computer numerically controlled machining”, Proceedings of the IMechE, Part B: Journal of Engineering Manufacture: Impact of energy efficiency on computer numerically controlled machining, Vol 224:4.

[4] Camahan, J.V. and Thurston, D.L., 2008. "Trade-off Modeling for Product and Manufacturing Process Design for the Environment”, Journal of Industrial Ecology, Vol 2:1, pp 79-92.

[5] Cus, F. and Balic, J., 2003. “Optimization of cutting process by GA approach, Robotics and Computer Integrated Manufacturing”, Vol 19: 1-2, pp. 113-121

[6] Dettmer, H.W., 2001. "Beyond Lean Manufacturing: Combining Lean and the Theory of Constraints for Higher Performance”, http://www.goalsys.com/books/documents/TOCandL eanPaper-rev.1.pdf/ Accessed April 27, 2010.

[7] US Department of Commerce, http://www.commerce.gov/ Accessed April 27, 2010.

[8] Energy Information Administration, http://www.eia.doe.gov/ Accessed April 27, 2010.

[9] European Commission, 2009. Updated work programme 2009 and work programme 2010, Cooperation theme 3, ICT - Information and Communications Technologies.

ftp://ftp.cordis.europa.eu/pub/fp7/ict/docs/ict-wp2009-10_en.pdf/ Accessed April 27, 2010.

[10] Fujimoto, T. 2007. "Innovation of Manufacturing (Monozukuri)Systems”,

http://www.iftech.or.jp/center/psr/archives/isjapan200 7/pdf/session_4/fujimoto/fujimoto_ppt.pdf/ Accessed April 27, 2010

[11] Jawahr, I.S., and Wang, X., 2006. "Development of hybrid predictive models and optimization techniques for machining operations”, Journal of Material
Processing Technology, Vol 185: 3, pp. 46-59.

Jerard, R.B., Fussell, B.K. and Ercan, M.T., 2001. "Online Optimization of Cutting Conditions for NC Machining”, Proceedings of design, Manufacturing \& Industrial Innovation Research Conference. http://www.rh.edu/ ernesto/F2005/MAMS/zpapers/je rard.pdf/ Accessed April 27, 2010.

[13] Jovane, F., Westkämper, E. and Williams, D., 2009 The ManuFuture Road: Towards Competitive and Sustainable High-Adding Value Manufacturing, Springer, ISBN 3540770119

[14] Lee, Y.H., Yang, B.H. and Moon, K.S., 1999. “An economic machining process model using fuzzy nonlinear programming and neural network”, International Journal of Production Research, Vol 37:7, pp. 83-847.

[15] Mani, M., Lyons, K.W., Rachuri, S., Subrahmanian, E. and Sriram, R., 2008. "Introducing Sustainability Early into manufacturing Process Planning”, Proceedings of the 14th International Conference on Manufacturing Science and Engineering, Evanston, IL.

[16] MTConnect ${ }^{\mathrm{TM}}$, Association for Manufacturing Technology, http://www.MTConnect ${ }^{\mathrm{TM}}$.org/ Accessed April 27, 2010.

[17] National Council for Advanced Manufacturing http://www.nacfam.org/PolicyInitiatives/Sustainable Manufacturing/tabid/64/Default.aspx/ Accessed April 27, 2010.

[18] Shahbazpour, M. and Seidel, R.H., 2006. "Using Sustainability for Competitive Advantage”, LCE 2006, pp. 287-292.

[19] http://trade.gov/competitiveness/sustainable manufacturing/metrics.asp/ Accessed April 27, 2010. 